BENTHM OPEN
CrossMark
Content list available at: www.benthamopen.com/TOCMJ/
DOI: $10.2174 / 1874192401610010089$

\title{
Long-term Arrhythmia Monitoring in Cryptogenic Stroke: Who, How, and for How Long?
}

\author{
Mayra Montalvo', Rushna $\mathrm{Ali}^{2}$, Brian Silver ${ }^{3}$ and Muhib Khan ${ }^{3, *}$ \\ ${ }^{I}$ Neuromodulation Center, Spaulding Rehabilitation Hospital, Harvard Medical School, $96 / 7913^{\text {th }}$ Street, Boston, MA \\ 02129, USA \\ ${ }^{2}$ Department of Neurosurgery, Henry Ford Health System, 2799 W. Grand Blvd, Detroit, MI 48202, USA \\ ${ }^{3}$ Department of Neurology, Warren Alpert Medical School, Brown University, 110 Lockwood Street, Suite 324, Prov- \\ idence, RI 02903, USA
}

Received: September 29, 2015

Revised: October 08, 2015

Accepted: November 25, 2015

\begin{abstract}
Cryptogenic stroke and transient ischemic attack (TIA) account for approximately one-third of stroke patients [1]. Paroxys-mal atrial fibrillation (PAF) has been suggested as a major etiology of these cryptogenic strokes [2, 3]. PAF can be difficult to diagnose because it is intermittent, often brief, and asymptomatic. PAF might be more prevalent than persistent atrial fibrillation in stroke and TIA patients, especially in younger populations [4, 5]. In patients with atrial fibrillation, anticoagulation provides significant risk reduction [6]. A new generation of oral anticoagulants has been approved for non-valvular atrial fibrillation, providing a variety of therapeutic options for patients with atrial fibrillation and risk of stroke [7].

Prior practice included an admission electrocardiogram (ECG) and continuous telemetry monitoring while in hospital [8]. However, this approach can lead to under-detection of brief asymptomatic events, which can occur at variable intervals, often outside of the hospital setting. Technological advancements have led to devices that can monitor cardiac rhythms outside of the hospital for longer durations resulting in higher yield of detection of atrial fibrillation events.
\end{abstract}

Moreover, recent studies show that the normal monitoring time for arrhythmias may be shorter than ideal in order to detect atrial fibrillation, and increasing this interval could significantly improve detection of atrial fibrillation in these patients $[9,10]$.

The aim of this study is to review the literature in order to define what subgroup of patients, with what methodologies, and for how long monitoring for atrial fibrillation should occur in patients presenting with cryptogenic stroke.

Keywords: Atrial fibrillation, ischemic stroke, monitoring, oral anticoagulation.

\section{PATIENT SELECTION}

In order for long-term monitoring to have a reasonable yield, factors that can more reliably predict PAF should be considered. Several studies have identified multiple predictors of PAF including advanced age, female gender, diabetes, hypertension, sleep apnea, premature atrial complexes (PACs) on ECG, abnormal p-wave morphology, left atrial dilatation, reduced left ventricular ejection fraction (EF), congestive heart failure, valvular heart disease, coronary artery disease, higher stroke severity on the National Institute of Health Stroke Scale (NIHSS), non-lacunar anterior circulation infarcts on neuroimaging, and cortical infarcts on neuroimaging [11 - 21].

It is important to note that all of these parameters are tested for under standard stroke unit protocols for patients with cryptogenic stroke. The demographics and history are obtained at initial assessment. Cardiac parameters can be obtained through ECG and transthoracic echocardiogram. Neuroimaging parameters can be obtained through routine

\footnotetext{
* Address correspondence to this author at the Department of Neurology, Warren Alpert Medical School, Brown University, 110 Lockwood Street, Suite 324, Providence, RI 02903, USA; Tel: 401-444-5055; Fax: 401-444-8781; Email: muhib_khan@brown.edu
} 
evaluation of these patients. Sleep studies, which are not routinely performed, can be added to the evaluation of patients either in the hospital or during subsequent visits.

These predictors have been consolidated into scoring scales to provide a predictive model [16, 20, 22]. The STAF prediction model includes variables such as age, NIHS score, left atrial dilatation and absence of cranial stenosis or lacunar syndrome. The LADS scale includes left atrial diameter, age, diagnosis of stroke and smoking status. Although STAF yields a high sensitivity and specificity, the variability of inter-rater reliability for NIHSS and TOAST may lower the efficacy of this scale in different hospital settings [16, 20, 22]. The shortcomings of all these scales is that they have relatively low accuracy.

In light of recent results showing that long-term monitoring was effective at detecting atrial fibrillation in patients with cryptogenic stroke [9, 10], we suggest that all patients with previous cryptogenic stroke based on hospital evaluation should be monitored, regardless of their scores in the aforementioned scales.

\section{DEVICE SELECTION}

Routine ECG is part of the initial evaluation for patients with stroke, but the yield for PAF is low. Continuous cardiac telemetry while the patient is in the hospital for stroke improves this yield [23 - 25]. There are multiple devices available for detecting PAF. Holter monitors are battery operated and record 2 to 3 different leads. These devices record data that is then analyzed with the help of software to identify rhythm abnormalities. Patient-activated event markers and time markers are also used to improve yield. Recorded tracings are then interpreted by cardiologists [26]. However, a large number of patients with PAF will remain undetected when Holter is used because of a short monitoring duration.

Therefore, long term monitoring devices have been developed to address this issue [27]. These devices are worn continuously and come in a variety of modalities. External loop or event recorders monitor the ECG into a memory buffer loop that freezes upon patient activation, permitting capture of the ECG for several minutes before and after activation. The monitor transmits these recordings by telephone by converting ECG data to audio signals. A central receiving station reconstructs the electric signal into a conventional ECG recording for interpretation by cardiologists $[9,26,28]$.

The second option, mobile cardiac outpatient telemetry systems, can also provide detection of asymptomatic PAF, whereas external loop recorders can only provide detection of symptomatic events. Patients wear a small transmitting pendant that is connected to 3 ECG electrodes. The pendant transmits real-time ECG data to a cell phone-sized monitor that analyzes the rhythm. These events are transmitted via the cellular network to a laboratory where technicians read the episodes. Predetermined physician-set monitoring thresholds and response parameters are used to generate alerts. Patients can also activate the monitor to report symptomatic events [4, 29]. Algorithms have been developed that analyze R-R interval variability, QRS morphology, and P-wave presence to screen for PAF [30]. The settings generate automatic alerts that facilitate detection of asymptomatic arrhythmias [26, 27, 29].

Finally, since the previous devices are surface recording devices that are potentially prone to artifacts, lead failure and patient non-compliance. Implantable loop recorders are helpful in this regard. These devices are implanted subcutaneously to overcome the aforementioned limitations. Current devices are capable of recording up to 50 minutes of ECG. These data are then transmitted over the telephone or wirelessly for physician review. They can be implanted for up to 3 years and can be explanted once a diagnosis is made or the battery life has ended [10, 26, 31].

The use of Holter monitoring has improved the detection of these events, but only provides recording capabilities for a 48-hour period [17, 24, 32, 33]. In contrast, long monitoring devices can record a longer period (3-6 weeks) improving the chance of diagnosing atrial fibrillation [23]. To our knowledge there is no study comparing sensitivity and specificity for the different devices. Detection rates of atrial fibrillation range between 5-25\% among the different devices. These studies have different recording times, eligibility criteria and outcomes, hindering a useful comparison between the different modalities [10, 27, 28, 31,34].

Mobile health (mHealth) applications are also available for smartphones that allow patients to check for AF autonomously. The app is FDA-cleared and is currently available for patients to utilize for self-reporting of AF. Preliminary studies indicate high use rates of the app and general patient satisfaction and improved health awareness [35], although it should be noted that this is a supplemental diagnostic tool that is still being evaluated. In general, mHealth software and mobile applications have a great potential to involve patients in their own diagnosis and treatment, and integrate physicians into the digitally connected platform of modern communications [36]. This could result in decreased costs, increased efficiency and quality of medical care, and broader access to care, but must also be 
tempered by efforts to ensure patient privacy and minimize safety risks. Overall we believe it is a useful tool but serves only as a supplement to the current standard monitoring devices.

\section{DURATION}

The appropriate duration of monitoring for arrhythmia is not well defined [27]. However, recent studies suggest that longer duration is better [37]. The yield with surface event monitors ranges between 5\%-25\%, [10, 27] with an overall detection rate of $11.5 \%$ [38]. The variability in detection rates is due to different monitoring durations. Moreover, the criteria for events to be diagnosed as atrial fibrillation is also variable, with some studies using $>30$ seconds event duration as a definite threshold for atrial fibrillation [27]. Recently published trials have highlighted the need for more long-term monitoring $[9,10]$.

The Atrial Fibrillation in Patients with Cryptogenic Stroke (EMBRACE) trial randomized patients to long-term monitoring (30 days of event monitoring) vs. conventional monitoring (24 hours of Holter monitoring). This trial found a significant difference in atrial fibrillation detection $(16.1 \%$ vs. $3.2 \% ; P<0.001)$ [9].

The Cryptogenic Stroke and Underlying Atrial Fibrillation (CRYSTAL-AF) trial randomized patients to implanted cardiac monitor (ICM) vs. conventional routine monitoring. This trial found a significant difference in atrial fibrillation detection both at 6 months $(8.9 \%$ vs. $1.4 \% ; P<0.001)$ and 12 months $(12.4 \% v s .2 .0 \% ; P<0.001)$ [10]. At 3 years, approximately $30 \%$ of implanted patients were found to have atrial fibrillation raising the question of whether the atrial fibrillation detected after stroke is causal, a result, or an unrelated event.

It is important to note that both of these trials used a threshold of $>30$ seconds to define atrial fibrillation events. These trials provide much needed evidence for the effectiveness of long-term monitoring. Importantly, outpatient monitoring after ischemic stroke can identify patients with PAF who will benefit from anticoagulation and it has shown to be cost-effective after ischemic stroke [39]. We suggest 30-day event monitoring for all patients with cryptogenic stroke. Further monitoring with ICM can be done in patients who have continued neurological events with previously negative 30-day monitoring results.

\section{CONCLUSION}

Advancements in technology have led to improved detection of atrial fibrillation, which assists physicians in management of patients with previously defined cryptogenic stroke. We recommend that patients with cryptogenic stroke undergo long-term cardiac rhythm monitoring for at least 30 days. As recent studies have reported that detection rates of atrial fibrillation increase with time, further research is needed to determine the ideal duration for monitoring patients with cryptogenic stroke.

\section{CONFLICT OF INTEREST}

The authors confirm that this article content has no conflicts of interest.

\section{ACKNOWLEDGEMENTS}

Declared none.

\section{REFERENCES}

[1] Kolominsky-Rabas PL, Weber M, Gefeller O, Neundoerfer B, Heuschmann PU. Epidemiology of ischemic stroke subtypes according to TOAST criteria: incidence, recurrence, and long-term survival in ischemic stroke subtypes: a population-based study. Stroke 2001; 32(12): $2735-40$.

[http://dx.doi.org/10.1161/hs1201.100209] [PMID: 11739965]

[2] Camm AJ, Corbucci G, Padeletti L. Usefulness of continuous electrocardiographic monitoring for atrial fibrillation. Am J Cardiol 2012; 110(2): 270-6. [http://dx.doi.org/10.1016/j.amjcard.2012.03.021] [PMID: 22503584]

[3] Charitos EI, Ziegler PD, Stierle U, et al. Atrial fibrillation burden estimates derived from intermittent rhythm monitoring are unreliable estimates of the true atrial fibrillation burden. Pacing Clin Electrophysiol 2014; 37(9): 1210-8. [http://dx.doi.org/10.1111/pace.12389] [PMID: 24665972]

[4] Rabinstein AA, Fugate JE, Mandrekar J, et al. Paroxysmal atrial fibrillation in cryptogenic stroke: a case-control study. J Stroke Cerebrovasc Dis $2013 ; 22(8): 1405-11$.

[http://dx.doi.org/10.1016/j.jstrokecerebrovasdis.2013.05.013] [PMID: 23791469] 
[5] Rizos T, Wagner A, Jenetzky E, et al. Paroxysmal atrial fibrillation is more prevalent than persistent atrial fibrillation in acute stroke and transient ischemic attack patients. Cerebrovasc Dis 2011; 32(3): 276-82. [PMID: 21893980]

[6] Hart RG, Pearce LA, Aguilar MI. Meta-analysis: antithrombotic therapy to prevent stroke in patients who have nonvalvular atrial fibrillation. Ann Intern Med 2007; 146(12): 857-67. [http://dx.doi.org/10.7326/0003-4819-146-12-200706190-00007] [PMID: 17577005]

[7] Potpara TS, Lip GY, Apostolakis S. New anticoagulant treatments to protect against stroke in atrial fibrillation. Heart 2012; $98(18)$ : 1341-7. [http://dx.doi.org/10.1136/heartjnl-2012-301841] [PMID: 22730480]

[8] Jauch EC, Saver JL, Adams HP Jr, et al. American Heart Association Stroke Council; Council on Cardiovascular Nursing; Council on Peripheral Vascular Disease; Council on Clinical Cardiology. Guidelines for the early management of patients with acute ischemic stroke: a guideline for healthcare professionals from the American Heart Association/American Stroke Association. Stroke 2013; 44(3): 870-947. [http://dx.doi.org/10.1161/STR.0b013e318284056a] [PMID: 23370205]

[9] Gladstone DJ, Spring M, Dorian P, et al. Atrial fibrillation in patients with cryptogenic stroke. N Engl J Med 2014; $370(26)$ : $2467-77$. [http://dx.doi.org/10.1056/NEJMoa1311376] [PMID: 24963566]

[10] Sanna T, Diener H-C, Passman RS, et al. Cryptogenic stroke and underlying atrial fibrillation. N Engl J Med 2014; 370(26): $2478-86$. [http://dx.doi.org/10.1056/NEJMoa1313600] [PMID: 24963567]

[11] Tayal AH, Tian M, Kelly KM, et al. Atrial fibrillation detected by mobile cardiac outpatient telemetry in cryptogenic TIA or stroke. Neurology 2008; 71(21): 1696-701. [http://dx.doi.org/10.1212/01.wnl.0000325059.86313.31] [PMID: 18815386]

[12] Miller DJ, Khan MA, Schultz LR, et al. Outpatient cardiac telemetry detects a high rate of atrial fibrillation in cryptogenic stroke. J Neurol Sci 2013; 324(1-2): 57-61. [http://dx.doi.org/10.1016/j.jns.2012.10.001] [PMID: 23102659]

[13] Bhatt A, Majid A, Razak A, Kassab M, Hussain S, Safdar A. Predictors of occult paroxysmal atrial fibrillation in cryptogenic strokes detected by long-term noninvasive cardiac monitoring. Stroke Res Treat 2011. [http://dx.doi.org/10.4061/2011/172074]

[14] Elijovich L, Josephson SA, Fung GL, Smith WS. Intermittent atrial fibrillation may account for a large proportion of otherwise cryptogenic stroke: a study of 30-day cardiac event monitors. J Stroke Cerebrovasc Dis 2009; 18(3): 185-9. [http://dx.doi.org/10.1016/j.jstrokecerebrovasdis.2008.09.005] [PMID: 19426887]

[15] Gaillard N, Deltour S, Vilotijevic B, et al. Detection of paroxysmal atrial fibrillation with transtelephonic EKG in TIA or stroke patients. Neurology 2010; 74(21): 1666-70.

[http://dx.doi.org/10.1212/WNL.0b013e3181e0427e] [PMID: 20498434]

[16] Malik S, Hicks WJ, Schultz L, et al. Development of a scoring system for atrial fibrillation in acute stroke and transient ischemic attack patients: the LADS scoring system. J Neurol Sci 2011; 301(1-2): 27-30. [http://dx.doi.org/10.1016/j.jns.2010.11.011] [PMID: 21130468]

[17] Stahrenberg R, Edelmann F, Haase B, et al. Transthoracic echocardiography to rule out paroxysmal atrial fibrillation as a cause of stroke or transient ischemic attack. Stroke 2011; 42(12): 3643-5. [http://dx.doi.org/10.1161/STROKEAHA.111.632836] [PMID: 21998056]

[18] Wallmann D, Tüller D, Wustmann K, et al. Frequent atrial premature beats predict paroxysmal atrial fibrillation in stroke patients: an opportunity for a new diagnostic strategy. Stroke 2007; 38(8): 2292-4. [http://dx.doi.org/10.1161/STROKEAHA.107.485110] [PMID: 17585079]

[19] Kamel H, Bartz TM, Longstreth WT Jr, et al. Association between left atrial abnormality on ECG and vascular brain injury on MRI in the Cardiovascular Health Study. Stroke 2015; 46(3): 711-6. [http://dx.doi.org/10.1161/STROKEAHA.114.007762] [PMID: 25677594]

[20] Brunner KJ, Bunch TJ, Mullin CM, et al. Clinical predictors of risk for atrial fibrillation: implications for diagnosis and monitoring Mayo clinic proceedings. Elsevier 2014; pp. 1498-505.

[21] Neilan TG, Farhad H, Dodson JA, et al. Effect of sleep apnea and continuous positive airway pressure on cardiac structure and recurrence of atrial fibrillation. J Am Heart Assoc 2013; 2(6): e000421. [http://dx.doi.org/10.1161/JAHA.113.000421] [PMID: 24275628]

[22] Suissa L, Bertora D, Lachaud S, Mahagne MH. Score for the targeting of atrial fibrillation (STAF): a new approach to the detection of atrial fibrillation in the secondary prevention of ischemic stroke. Stroke 2009; 40(8): 2866-8. [http://dx.doi.org/10.1161/STROKEAHA.109.552679] [PMID: 19461041]

[23] Vivanco Hidalgo RM, Rodríguez Campello A, Ois Santiago A, Cuadrado Godia E, Pont Sunyer C, Roquer J. Cardiac monitoring in stroke units: importance of diagnosing atrial fibrillation in acute ischemic stroke. Rev Esp Cardiol 2009; 62(5): 564-7. [http://dx.doi.org/10.1016/S0300-8932(09)71037-1] [PMID: 19406071]

[24] Sposato LA, Klein FR, Jáuregui A, et al. Newly diagnosed atrial fibrillation after acute ischemic stroke and transient ischemic attack: importance of immediate and prolonged continuous cardiac monitoring. J Stroke Cerebrovasc Dis 2012; 21(3): 210-6. [http://dx.doi.org/10.1016/j.jstrokecerebrovasdis.2010.06.010] [PMID: 20727789] 
[25] Rem JA, Hachinski VC, Boughner DR, Barnett HJ. Value of cardiac monitoring and echocardiography in TIA and stroke patients. Stroke 1985; 16(6): 950-6. [http://dx.doi.org/10.1161/01.STR.16.6.950] [PMID: 4089926]

[26] Zimetbaum PJ, Josephson ME. The evolving role of ambulatory arrhythmia monitoring in general clinical practice. Ann Intern Med 1999; 130(10): 848-56. [http://dx.doi.org/10.7326/0003-4819-130-10-199905180-00020] [PMID: 10366376]

[27] Khan M, Miller DJ. Detection of paroxysmal atrial fibrillation in stroke/tia patients. Stroke Res Treat 2013.

[28] Higgins P, MacFarlane PW, Dawson J, McInnes GT, Langhorne P, Lees KR. Noninvasive cardiac event monitoring to detect atrial fibrillation after ischemic stroke: a randomized, controlled trial. Stroke 2013; 44(9): 2525-31. [http://dx.doi.org/10.1161/STROKEAHA.113.001927] [PMID: 23899913]

[29] Joshi AK, Kowey PR, Prystowsky EN, et al. First experience with a Mobile Cardiac Outpatient Telemetry (MCOT) system for the diagnosis and management of cardiac arrhythmia. Am J Cardiol 2005; 95(7): 878-81. [http://dx.doi.org/10.1016/j.amjcard.2004.12.015] [PMID: 15781022]

[30] Korzinov L. Cardiac monitoring. Google Patents US 7941207 B2, 2007.

[31] Cotter PE, Martin PJ, Ring L, Warburton EA, Belham M, Pugh PJ. Incidence of atrial fibrillation detected by implantable loop recorders in unexplained stroke. Neurology 2013; 80(17): 1546-50. [http://dx.doi.org/10.1212/WNL.0b013e31828f1828] [PMID: 23535493]

[32] Barthélémy JC, Féasson-Gérard S, Garnier P, et al. Automatic cardiac event recorders reveal paroxysmal atrial fibrillation after unexplained strokes or transient ischemic attacks. Ann Noninvasive Electrocardiol 2003; 8(3): 194-9. [http://dx.doi.org/10.1046/j.1542-474X.2003.08305.x] [PMID: 14510653]

[33] Jabaudon D, Sztajzel J, Sievert K, Landis T, Sztajzel R. Usefulness of ambulatory 7-day ECG monitoring for the detection of atrial fibrillation and flutter after acute stroke and transient ischemic attack. Stroke 2004; 35(7): 1647-51. [http://dx.doi.org/10.1161/01.STR.0000131269.69502.d9] [PMID: 15155965]

[34] Manina G, Agnelli G, Becattini C, Zingarini G, Paciaroni M. 96 hours ECG monitoring for patients with ischemic cryptogenic stroke or transient ischaemic attack. Intern Emerg Med 2014; 9(1): 65-7. [http://dx.doi.org/10.1007/s11739-012-0755-3] [PMID: 22249917]

[35] Saxon LA. Ubiquitous wireless ECG recording: a powerful tool physicians should embrace. J Cardiovasc Electrophysiol 2013; 24(4): 480-3. [http://dx.doi.org/10.1111/jce.12097] [PMID: 23421574]

[36] Cortez NG, Cohen IG, Kesselheim AS. FDA regulation of mobile health technologies. N Eng1 J Med 2014; 371 (4): $372-9$. [http://dx.doi.org/10.1056/NEJMhle1403384] [PMID: 25054722]

[37] Silver B. Cryptogenic stroke and atrial fibrillation. N Engl J Med 2014; 371(13): 1259-62. [http://dx.doi.org/10.1056/NEJMc1409495] [PMID: 25251622]

[38] Kishore A, Vail A, Majid A, et al. Detection of atrial fibrillation after ischemic stroke or transient ischemic attack: a systematic review and meta-analysis. Stroke 2014; 45(2): 520-6. [http://dx.doi.org/10.1161/STROKEAHA.113.003433] [PMID: 24385275]

[39] Kamel H, Hegde M, Johnson DR, Gage BF, Johnston SC. Cost-effectiveness of outpatient cardiac monitoring to detect atrial fibrillation after ischemic stroke. Stroke 2010; 41(7): 1514-20. [http://dx.doi.org/10.1161/STROKEAHA.110.582437] [PMID: 20508188]

(C) Montalvo et al.; Licensee Bentham Open.

This is an open access article licensed under the terms of the Creative Commons Attribution-Non-Commercial 4.0 International Public License (CC BY-NC 4.0) (https://creativecommons.org/licenses/by-nc/4.0/legalcode), which permits unrestricted, non-commercial use, distribution and reproduction in any medium, provided the work is properly cited. 